\title{
Sobre el léxico de la administración en el siglo XVIII
}

\author{
Millán URdiales \\ Universidad de Oviedo
}

\section{Introducción}

La lectura de textos dieciochescos como los Vecindarios del Marqués de la Ensenada se presta a ciertas reflexiones por parte del lector actual. Es innegable que el léxico, en todas las lenguas y en todos los tiempos, está íntimamente asociado a los objetos materiales o ideales que en tales lenguas y en tales momentos existen. Cuando se trata de objetos materiales, las voces que los designan suelen morir con la desaparición del objeto, aunque esa muerte no siempre coincida automáticamente con la desaparición de este y pueda durar algo más. Otras veces ocurre que el objeto desaparecido se ve sustituido por otro que funcionalmente le sustituye con más o menos exactitud y en ese caso la voz que designaba al primer objeto sigue igual de viva, o más, al aplicarse al nuevo objeto sustitutor. Esto es lo que ha ocurrido, por ejemplo, con voces como coche o carro, que hoy designan en el español peninsular y ultramarino respectivamente al automóvil. En el campo de los objetos ideales, este tipo de pervivencia es mucho más frecuente, porque se trata de instituciones, de funciones, de unidades administrativas, y aunque todas ellas vayan constantemente cambiando con los cambios que experimenta la sociedad, es decir, el grupo humano en el que están insertas, las voces en cuestión siguen designando a las nuevas realidades. Este es el caso de voces como juez, o alcalde, o gobernador, y de los abstractos correspondientes como judicatura, juzgado, alcaldía, gobernación. Parece también innegable que mientras más alejados en el tiempo estén esos conceptos, más distancia hay o puede haber entre la sustancia semántica de la 
misma voz en aquel momento del pasado y en este del presente: voces como concilio o ministro son buen ejemplo de esto. El siglo XVIII no es una época remota, pero los cambios que se han producido en el mundo en los dos últimos siglos han sido tales que, muy a menudo, el lector actual de textos de entonces encuentra graves dificultades para entenderlos bien; el problema, como acabamos de decir, reside muchas veces en que las voces empleadas hoy siguen vivas pero designando otras realidades.

El Vecindario de Ensenada ${ }^{1}$ es una enumeración o lista de los vecinos que vivían en cada uno de los núcleos de población que constituían la Corona de Castilla. Ocurre pues, que voces como vecindario y vecino han variado de significación, debido sobre todo al hecho de que hoy vivimos, la inmensa mayoría, en núcleos de población muy distintos de los existentes en el siglo XVIII.

\section{Circunstancias y características geográficas}

Aunque el nombre España y aun las Españas se utilizasen en muchos contextos no está de más observar aquí que el listado de vecinos en cuestión, a mediados del siglo xVIII, recibe el nombre de Vecindario de Ensenada para la Corona de Castilla ${ }^{2}$. De la tremenda heterogeneidad de las relaciones políticoadministrativas que regían a tal comunidad (y de cuya unidad solo la lengua escrita de los textos que las regulan parecen dar prueba), es buen ejemplo el léxico de tales textos. Los territorios de la Corona de Castilla aparecen repartidos en 22 Provincias. Los nombres de la mayor parte de estas siguen designando hoy provincias españolas, aunque sus territorios respectivos y sus límites sean muy distintos: las del siglo XVIII eran, casi todas, mucho más grandes; los nombres de otras son hoy regiones, o como decimos actualmente, Autonomías: así ocurre con Galicia y con Extremadura, y en parte, con La Mancha, hoy Castilla-La Mancha; en un caso se trata de un nombre que hoy designa sólo una ciudad, Toro.

La localización de las Provincias del Vecindario de Ensenada no tiene hoy más referencia segura que el nombre de lo que ha venido a ser la capital de cada una de ellas, pero sus territorios respectivos eran muy distintos de los de las provincias actuales, en extensión y en límites. Elaborar mapas de dichas Provincias dieciochescas sería tarea muy laboriosa pero de capital importancia. Sólo de algunas de tales Provincias hay mapas llevados a cabo por investigadores

\footnotetext{
${ }^{1}$ Vecindario de Ensenada, 1759. 4 vols. Prólogo e introducción, Antonio Domínguez Ortiz, Concepción Camarero, Jesús Campo, Madrid, Tabapress, S.A., 1991.

${ }^{2}$ Ibid. p. XXI.
} 
actuales: así ocurre con la Provincia de Salamanca, cuyo mapa elaboró en su día María Dolores Mateos ${ }^{3}$.

Aunque los editores del Vecindario presentan las 22 Provincias en orden alfabético, nosotros creemos más indicado seguir un criterio geográfico que sirve, al mismo tiempo, para ilustrar aspectos históricos. Podemos así separar en dos mitades a estas 22 Provincias, estableciendo la divisoria en las cordilleras centrales de la Península; podría así hablarse, desde un punto de vista geográfico e histórico, de una España del Norte y de una España del Sur, sin que tal división prejuzgue cosa alguna. Curiosamente, con arreglo a los nombres y a la localización de las Provincias del Vecindario de Ensenada, habría once en el norte y otras once en el sur:

$\begin{array}{ll}\text { Norte } & \text { Sur } \\ \text { Galicia } & \text { Guadalajara } \\ \text { León } & \text { Madrid } \\ \text { Burgos } & \text { Cuenca } \\ \text { Palencia } & \text { Toledo } \\ \text { Zamora } & \text { Extremadura } \\ \text { Toro } & \text { Mancha } \\ \text { Valladolid } & \text { Murcia } \\ \text { Salamanca } & \text { Jaén } \\ \text { Ávila } & \text { Córdoba } \\ \text { Segovia } & \text { Granada } \\ \text { Soria } & \text { Sevilla }\end{array}$

Debe advertirse enseguida que León incluía Asturias, Burgos, Cantabria y Logroño y se extendía por el Este hasta el Ebro, igual que Soria; las ocho provincias andaluzas eran entonces cuatro: Sevilla comprendía, además de la actual, las provincias de Huelva y Cádiz, y Granada las de Málaga y Almería. De la observación de este Vecindario de Ensenada se sacan pronto dos conclusiones:

a) La repartición de la población de lo que convencionalmente llamamos aquí España norteña y España sureña (siempre en la Corona de Castilla exclusivamente) era tan regular en ambas «mitades» que la suma del total de cada grupo de provincias, tal como los calculan los editores, es casi la misma ${ }^{4}$ : en la que llamamos mitad norteña había 3.288.010 habitantes y en la sureña 3.282.489.

b) En contraste con esta paridad, la cantidad de poblaciones o núcleos de población era enormemente distinta en una y otra zona de la Corona de Casti-

\footnotetext{
${ }^{3}$ Vid. Maria Dolores Mateos, «La España del Antiguo Régimen», en Estudios Históricos, ed. por Miguel Artola, Fasc., Salamanca, Universidad de Salamanca, 1966.

${ }^{4}$ Op. cit. Cuadro 12, Vol. I, p. CII.
} 
lla: contando el número de páginas que ocupan los núcleos de población de cada una de las dos zonas se observará la diferencia; esta es la lista por Provincias:

\begin{tabular}{|c|c|c|c|c|c|}
\hline Galicia & 262 & págs. & Guadalajara & 20 & págs. \\
\hline León & 176 & “ & Madrid & 8 & “ \\
\hline Burgos & 128 & “ & Cuenca & 30 & “ \\
\hline Palencia & 23 & “ & Toledo & 24 & “" \\
\hline Zamora & 20 & “ & Extremadura & 30 & “" \\
\hline Toro & 21 & “ & Mancha & 8 & “ \\
\hline Valladolid & 37 & “ & Murcia & 6 & “ \\
\hline Salamanca & 72 & “ & Jaén & 8 & “6 \\
\hline Ávila & 18 & “ & Córdoba & 4 & “ \\
\hline Segovia & 35 & “ & Granada & 32 & $“$ \\
\hline Soria & 50 & “ & Sevilla & 16 & “6 \\
\hline Total & 842 & “ & Total & $186^{5}$ & 6 \\
\hline
\end{tabular}

Estos totales indican, aunque sea grosso modo, el distinto tipo de poblamiento entre la zona norteña y la zona sureña: esas enormes diferencias eran consecuencia de la geografía y de la propia historia nacional condicionada por los largos siglos de la llamada Reconquista. Aun teniendo en cuenta las diferencias de extensión posibles entre las Provincias de cada grupo respectivo de entonces y sus homónimas actuales, es evidente, por ejemplo, que en las llamadas Provincias de Galicia, de León y de Burgos había una cantidad ingente de aldeas y pueblos pequeños; en contraste con esto se observará que de las cuatro Provincias andaluzas de entonces, solo Granada (que incluía las actuales provincias de Málaga y Almería y que representa la Andalucía más montañosa), ofrecía unas cifras relativamente altas de pequeños núcleos de población. Sevilla, Córdoba y Jaén tenían núcleos de población muy grandes en comparación con los de la zona norteña; lo mismo cabe decir de Murcia. Esa diferencia en el tamaño de las poblaciones aún resulta más visible observando el llamado Anexo: Poblaciones de los Reinos de Castilla con más de 1000 vecinos y capitales de provincia, según el vecindario de Ensenada, «elaboración propia» de los editores ${ }^{6}$. En este cuadro, de una lista de 190 poblaciones, sólo 27 están en la zona norte; parece que en esta lista han omitido, quizá por olvido, los núcleos de población con más de 1.000 vecinos de la Provincia de León, que sin duda eran la ciudad de León, la de Oviedo, y quizás otras poblaciones asturianas (decimos quizá porque para Asturias se nos da siempre el número de vecinos de cada concejo como un todo, es decir, la capital del concejo y sus pueblos). Las primeras 6

\footnotetext{
${ }^{5}$ Op.cit. Vol. I, II, III, IV.

${ }^{6}$ Ibid. Vol. I. Págs. CVII-CXI.
} 
poblaciones de la zona norte en esa lista de 190 ocupan, en orden descendente, los siguientes lugares: 14 Valladolid, 15 Santiago, 21 Salamanca, 29 Segovia, 33 Palencia y 42 Burgos. Pasaban de 1.000 vecinos Oviedo y León y acaso otras poblaciones asturianas, como hemos dicho.

Desde la Edad Media los núcleos de población, por razones históricas y jurídicas, venían clasificándose en tres categorías: ciudades, villas y lugares. En este Vecindario de Ensenada, la repartición de esas tres categorías puede variar mucho de unas provincias a otras; así por ejemplo, en la zona meridional son mucho más abundantes las villas y las ciudades que en la zona norteña; y en la misma medida escasean los lugares: llama la atención que en el Vecindario de la Provincia de Córdoba, de 61 poblaciones registradas — poquísimas- hay 4 ciudades, 57 villas y ningún lugar; hay, sin embargo, dos despoblados, voz que aparece en muchas otras Provincias y cuya significación quizá designaba algo un tanto distinto de lo que entiende un lector actual. Como el poblamiento de las regiones meridionales hispánicas había tenido lugar sobre bases geográficas, culturales e históricas muy diferentes de las del resto de España y en especial de las más norteñas, se comprende el caso mencionado de Córdoba y el de otras Provincias andaluzas: en la de Jaén ocurría algo semejante: de 74 nombres, 5 eran ciudades, 63 villas y sólo 6 lugares; en el caso de Sevilla, las denominaciones son más variadas: de 234 poblaciones 15 eran ciudades, 160 villas, 26 lugares y 9 despoblados a secas; pero hay además 13 que son villa despoblada, 8 lugar despoblado y en 3 casos aparece una voz nueva, donadío. Por razones de geografía política, además de física, Granada era la Provincia andaluza con más núcleos de población de las cuatro y la única de ellas que ofrece la subdivisión territorial en Partidos, como veremos más adelante.

\section{Fórmulas de presentación de los vecindarios y su léxico}

La presentación de los vecindarios de cada Provincia tiene un carácter formulístico propio de la lengua administrativa en todas las épocas. La fórmula más frecuente de todas está redactada así:

Estado del número de Yndividuos que existen en esta Provincia con distinción de Partidos y Pueblos y de la clase a que cada uno corresponde, según resulta de las Respuestas Generales, Memoriales y Libros Originales formados para el establecimiento de la Única Contribución.

Las voces por nosotros subrayadas merecen algún comentario: la voz Estado sería en el español actual relación (recuérdese la palabra estadillo que aunque 
no figura en el Diccionario académico, se oye en numerosos contextos con significación semejante); el número de Yndividuos no corresponde al actual de habitantes sino al de vecinos o sujetos fiscales, que es lo que pretendía contar la Administración; la voz Provincia designaba un territorio cuyo nombre, salvo en tres casos, Galicia, Extremadura y La Mancha, era el de la ciudad histórica que se lo prestaba; la voz Pueblos tenía sin duda la acepción hoy viva de núcleo de población en general; la voz Partidos designaba las partes en que cada Provincia se subdividía, pero, como veremos después, no era general en todas las Provincias de la Corona de Castilla: en algunos casos aparece en la fórmula de presentación pero luego falta en la enumeración de los núcleos de población; la voz Partido se enriqueció en el siglo XIX con el adjetivo Judicial, expresión hoy viva y usual; la voz clase designa el concepto de clase social, es decir, la división antigua y tradicional entre nobles y pecheros; en muchos casos a la expresión Estado noble se oponía Estado General; la frase a que cada uno corresponde remite a Yndividuos; finalmente, se emplean tres nombres para designar las fuentes de la relación de vecinos: a) las Respuestas Generales al Interrogatorio de 40 preguntas que los Intendentes de cada Provincia habían ido obteniendo, pueblo por pueblo, entre 1750 y 1755; b) los Memoriales; c) los Libros Originales que, según parece, recibían también el nombre de libros de los cabezas de casa ${ }^{7}$ La Única Contribución era el impuesto fiscal que la Corona quería implantar en todos sus territorios, basado en el porcentaje de ingresos de cada vecino, unificando así la variadísima gama de impuestos, injusta por su propia irregularidad.

La fórmula arriba transcrita es la que, con ligeras variantes en algún caso, se emplea en las Provincias de Galicia, León, Burgos, Palencia, Zamora, Valladolid, Ávila, Guadalajara, Cuenca, Toledo, Extremadura, la Mancha, Granada y Jaén. Las otras ocho Provincias ofrecen otras fórmulas de presentación y dentro de estas hay dos grupos: Salamanca, Segovia y Sevilla, por una parte, y Toro, Soria, Madrid, Murcia y Córdoba, por otra. Comentarlas aquí en detalle resultaría demasiado prolijo, aunque serviría para mostrar que la heterogeneidad de los impuestos tenía su reflejo en la del soporte lingüístico que los describía.

La prosa administrativa tiene características peculiares en todas las lenguas y en todas las épocas; por una parte, el empleo de voces que designan conceptos abstractos, exige y se presta al empleo de cultismos; y por otra, el ejercicio de la autoridad que respalda tales textos fomenta el uso de expresiones solemnes y rotundas, todo ello envuelto en una sintaxis que, al pretender encapsular el mensaje entre dos pausas totales, cae fácilmente en la ampulosidad, con menoscabo de la claridad.

${ }^{7}$ Ibid. Vol. I. Págs XXV-XXXIV. 
Todos estos encabezamientos demuestran que los escribanos de los Intendentes o Contadores, o incluso estos mismos, eran víctimas de rutinarias enumeraciones memorísticas, sin que les preocupase lo bastante la perfecta comprensión del mensaje por parte de sus destinatarios. Bajo ese desorden lingüístico, late también una falta de fe en lo que están haciendo, probablemente inseparable de lo que en nuestros días ha venido a llamarse corrupción y que en la administración española se expresaba con aquella famosa frase, se manda pero no se cumple o algo parecido.

Todo esto contribuye a explicar la heterogeneidad (equivalente en este caso a irregularidad y a injusticia) que caracterizaba a la administración española, limitada ciertamente aquí a la Corona de Castilla. Tales defectos explican hasta cierto punto los que han seguido afectando a la administración y a las instituciones de la nación en general durante los dos siglos y medio siguientes.

\section{El léxico de las divisiones y subdivisiones territoriales}

La heterogeneidad del léxico referente a los núcleos de población y a los diversos tipos de subdivisión del territorio no se debe a la incapacidad de los Intendentes que dirigen la redacción del Vecindario de cada Provincia, sino que refleja una variedad real, fruto de la diversidad geográfica de las tierras hispánicas y también de las distintas circunstancias históricas que acompañaron a esos territorios, hasta llegar a ser las Provincias en cuestión dentro de la Corona de Castilla; piénsese que, antes y junto a esta expresión, habían existido y seguían usándose aún otros títulos, como los que daban nombre a los numerosos Reinos que habían ido incorporándose a la Corona de Castilla: Reino de Asturias, de Galicia, de León, etc., etc.

A pesar de la mencionada heterogeneidad cabe hablar también de cierta homogeneidad. A mediados del siglo xvIII gozan de vitalidad voces como ciudad, villa y lugar, representantes sin duda de diferentes realidades administrativas y jurídicas, además de la realidad que representaba el número de habitantes respectivo. La voz Provincia designaba un territorio del que era cabeza una de las tradicionales 21 ciudades «de voto de Cortes»; este número aumentó a 22 en el siglo XVIII con la creación de la Provincia llamada La Mancha, en palabras de A. Domínguez Ortiz, «el único esfuerzo que hicieron los gobernantes del xVIII por adecuar mejor la distribución administrativa a la realidad geográfica ${ }^{8}$. La Corona de Castilla estaba pues dividida en 22 Provincias cuando Ense-

\footnotetext{
${ }^{8}$ Ibid. Vol. I. p. XVII.
} 
nada emprende, a mediados del siglo xvIII, la redacción del Censo, del Catastro y de los Vecindarios. La subdivisión inmediatamente inferior era la de Partido, voz que aparece como muy usada y que en el siglo XIX se reforzaría al verse acompañada del adjetivo Judicial, dando así lugar a un territorio administrativo y jurídico aún vigente.

Creo que es interesante notar y señalar, por una parte, cuáles son las Provincias que en sus listas de poblaciones añaden el dato indicador de su categoría con las iniciales respectivas C, V, L (y a veces Desp. para Despoblado) y por otra, ver cuáles son las palabras empleadas para describir las subdivisiones de los Partidos. Las Provincias en las que se lee C, V, L, junto a los nombres de los núcleos de población son estas diez: Palencia, Zamora, Toro, Ávila, Segovia, Madrid, Jaén, Córdoba, Granada, Sevilla.

En las presentaciones formulísticas del vecindario de cada Provincia, la expresión más repetida es ésta: «...con distinción de Partidos y Pueblos». Parece evidente que la voz Pueblos designaba de modo general a los núcleos de población cualquiera que fuese su rango, es decir, en la presentación, pues en el listado se especificaba ya cuándo se trataba de una ciudad o de una villa. La mencionada expresión aparece en el caso de las Provincias de Galicia, León, Burgos, Zamora, Valladolid, Ávila, Guadalajara, Toledo, Extremadura, Jaén y Granada, pero no es la única: en el caso de Salamanca, Madrid y La Mancha dice solo «...con distinción de Pueblos»; en el caso de Córdoba se dice: «...con distinción de Pueblos y despoblados». En otras Provincias el redactor, sin duda por torpeza lingüística y mental, mezcla o junta una categoría geográfica con una categoría social; así, en el caso de Cuenca se dice «...con distinción de Partidos, pueblos y clases»; en el de Murcia «...con distinción de clases y pueblos»; en el de Sevilla «...con distinción de Pueblos y clases»; en el de Toro «...con distinción de Valles y Jurisdicciones» y no aparece nunca la voz Partido; en el caso de Segovia dice: «...con distinción de Ziudades, Villas y Lugares»; $\sin$ embargo, después, los núcleos de población vienen agrupados en 14 Partidos más 1 Condado. En el caso de Soria, a causa de la distinta redacción de toda la presentación formulística se lee: «...el número de individuos que existen en las Ciudades, Villas y Lugares que componen dicha Provincia, con distinción de cada uno...». No aparece la voz Partido y los núcleos de población figuran en orden alfabético y por categorías, de más a menos. Todo esto por lo que se refiere a la fórmula de presentación de cada Provincia. Si observamos ahora los listados de las 22 Provincias podemos establecer tres grupos:

a) En el caso de Ávila, Madrid, La Mancha, Córdoba, Murcia, Jaén y Sevilla no hay subdivisiones ni figura tampoco la voz Partido. De estas siete Provincias La Mancha y Murcia tampoco acompañan sus listados con las iniciales C, V, L. 
b) Las Provincias que se subdividen en Partidos son estas doce: León (3), Burgos (14), Zamora (7), Toro (3), Valladolid (16), Salamanca (11), Segovia (14), Guadalajara (3), Cuenca (4), Toledo (5), Extremadura (8), y Granada (14).

c) Galicia, Palencia y Soria, representan casos aparte.

Así pues, en las Provincias del grupo a), salvo las dos mencionadas, los nombres de los núcleos de población aparecen en orden alfabético y seguidos de una de las iniciales C, V, L.

En las del grupo b), donde predominan claramente las norteñas, las denominaciones de las subdivisiones son muy variadas. La de León, que incluía Asturias, tenía tres Partidos, los de León, Ponferrada y Oviedo; en el de León aparecen como subdivisiones los nombres de abadía, concejo, condado, despoblados, gobernación (la de Cabrera), jurisdicción, lugares de propia jurisdicción, obispalía, quartos y alfozes, valle. Estas denominaciones figuran también en el Partido de Ponferrada, además de coto, merindad, préstamo (de Tabladillo), quintería y ribera. En el Partido de Asturias hay una peculiaridad, y es que las aldeas o parroquias, es decir, los núcleos de población más pequeños, reciben el nombre de coto; la otra voz que abunda es concejo y dado el número de vecinos, se infiere que en cada concejo entrarían diversas aldeas, caseríos o parroquias, cuyos nombres no se mencionan; también figuran las expresiones villa y jurisdicción, villa y concejo, coto y jurisdicción y el curiosísimo departamento de Berduzedo en el concejo de Allande. Esta peculiar descripción de los pueblos de Asturias es la causa de que aparezcan concejos con un alto número de vecinos: así ocurre, aparte de Oviedo, con Aller, Mieres, Langreo, Siero, Infiesto, Caso, Cangas de Onís, Llanes, Villaviciosa, Ribadesella, Gijón, Gozón, Avilés, Pravia, Grado, Luarca, Navia, Castropol, Tineo y Cangas de Tineo.

En la Provincia de Burgos los nombres de las subdivisiones de algunos Partidos, en especial en el de Laredo, son muy variados: abadía, alfoz, condado, hoz, junta, jurisdicción, marquesado, merindad e incluso el curioso provincia de Liébana. En la Provincia de Salamanca hay una serie de poblaciones bajo la etiqueta de Villas eximidas y otra llamada de Villas agregadas. En la de Segovia hay varios grupos de poblaciones que reciben el nombre de sexmos y en el Partido de Sepúlveda se habla de ochavos. En la de Extremadura, en vez de Lugares escriben Dehesas y Lugares. En la de Granada las voces Valle y Estado preceden a los nombres de sendos Partidos.

Las Provincias de Galicia, Palencia y Soria pueden considerarse como un caso aparte. Galicia es la Provincia con mayor número de núcleos de población, con enorme diferencia incluso sobre las que le siguen, León y Burgos; en la subdivisión no aparece la voz Partido, sino solo estos siete nombres: Betanzos, Coruña, Lugo, Mondoñedo, Orense, Santiago y Tuy; se observará que los 
cinco últimos designan sedes episcopales. Lo que hace única a Galicia es que, junto a cada topónimo o núcleo de población figura el nombre de un santo o santa, que designará la advocación bajo la cual está la parroquia: Andrade, San Martín; Friol, San Julián; Reinante, San Miguel; Oza, Santa Eulalia. En unos pocos casos, en lugar del santo o santa figura la voz villa o coto, o lugar o ciudad, o jurisdicción o población. En el caso de Palencia no aparece la voz Partido: en el listado de nombres, sin encabezamiento, figura en primer lugar Palencia seguido de Paredes de Monte su Arrabal y luego todas las poblaciones por orden alfabético; con el rango de Partido aparecen Valle de Boedo, Valle de Ojeda, Valle de Gama y varias Jurisdicciones; al final un grupo de Despoblados y otro de Ventas, Granjas y Términos con jurisdicción. En el caso de Soria tampoco aparece la voz Partido: los núcleos de población vienen en cuatro categorías: ciudad, villa, lugar y granja, ordenados alfabéticamente bajo cada letra: A, B, C, etc. Al final se nos dan los totales: Ciudades 4, Villas 132, Lugares 482, Granjas 30, más Términos Despoblados 83.

De todo esto parece deducirse que así como la voz Pueblo designaba un núcleo de población en general en toda la Corona de Castilla, la voz Partido, por razones sin duda diversas, no era empleada de modo general. Resulta significativo que entre las Provincias donde no se utiliza la voz Partido predominan claramente las sureñas, y a su vez, es en las norteñas donde se dan muchas más variantes para designar a las divisiones territoriales, donde hay una mayor diversidad y donde los criterios seguidos por los redactores del Vecindario parecen más subjetivos. Esto es particularmente notable en las Provincias de León, Burgos, Salamanca, Segovia y Palencia.

No deja de llamar la atención el hecho de que un Diccionario tan excelente como el de Autoridades no recoja muchas de las acepciones de estas voces y en algunos casos las voces mismas. Así por ejemplo, de una palabra como concejo trae Aut. varias acepciones: «Ayuntamiento o Junta de la Justicia y Regidores que gobiernan lo tocante al público de alguna Ciudad, Villa o Lugar»; «Se toma también por la casa donde se juntan los Alcaldes, Justicia y Regidores que componen el Ayuntamiento o Concejo»; concejo abierto: «La Junta que se hace en alguna Villa o Lugar a son de campana tañida, para que entren todos los que quisieren del Pueblo, por haverse de tratar alguna cosa de importancia, u de que puede resultar algún gravamen que comprehenda a todos: lo qual se executa a fin de que ninguno pueda reclamar después».

Estas acepciones, y en especial la última, explican que hasta tiempos bastante más recientes, a mediados de nuestro siglo, se empleasen expresiones como ir a concejo, estar en concejo y sobre todo tocar a concejo: era en efecto, un toque de campana, reconocido por todos, que convocaba a los vecinos a una reunión 
a fin de tratar algún asunto de interés común; había pueblos que incluso tenían un modesto edificio llamado casa de concejo, en la que se celebraban tales reuniones; la expresión y las propias reuniones han caído en desuso porque la administración ha pasado a apoyarse cada vez más en la letra escrita, y los alcaldes pedáneos, gracias a la movilidad que ha traído la motorización, despachan con el alcalde del Ayuntamiento en la localidad donde este resida sin ninguna dificultad. Se observará que falta en Aut. una acepción específica alusiva al territorio, al espacio geográfico; en las hablas leonesas la acepción territorial la cubre, no sé desde cuándo, la voz ayuntamiento y así se dice, por ejemplo: «El ayuntamiento de Gradefes tiene más de veinte pueblos». Esa misma palabra también designa, como en el español general, el edificio donde están instaladas las oficinas municipales.

De la voz coto trae el Diccionario de Autoridades varias acepciones pero sólo esta, «La dehesa o término cerrado, donde está vedado y defendido el entrar a pastar», se acerca a la que en el vecindario de Ensenada designa un territorio semejante al de concejo y frecuentísima en Asturias y León y menos en Galicia. Cierto es que el mismo Diccionario, s.v., Jurisdicción, dice así en la ac. $2^{\mathrm{a}}$ : «Se toma también por lo mismo que coto o término de un Lugar a otro, $\mathrm{u}$ de una Provincia a otra, en que se circunscribe el mando de alguno». De esta definición parece inferirse que la idea de territorio sí estaba en la mente del redactor, pero es un hecho que falta s.v. coto.

De la voz dehesa dice Aut. «Parte o porción de tierra, sin labranza, ni cultivo, destinada solamente para pasto de ganados»; esta es la significación actual, pero en el vecindario designa un núcleo de población junto a Lugar.

La voz departamento no está recogida por Aut. y sin embargo aparece, aunque sólo en una ocasión, en el caso de Asturias: «Departamento de Berducedo en el Concejo de Allande».

De la voz despoblado dice Aut.: «Usado como substantivo se toma por desierto, yermo o sitio que no está poblado». Sin embargo, en muchas Provincias del Vecindario figura al lado de Lugar, si bien con poquísimos vecinos.

De la voz donadío dice Aut.: «Lo mismo que Donación. Es voz antiquada». No hay ninguna alusión a la idea de territorio que es la que tiene en la Provincia de Sevilla.

La significación territorial falta en el Diccionario de Autoridades en las voces siguientes, voces que aparecen con otras acepciones: gobernación (Gobernación de Cabrera, en la Prov. de León), hoz (Burgos), junta (Burgos), ochavo (Segovia), préstamo (Préstamo de Tabladillo, Ponferrada), quartos (quartos y alfozes, Astorga), ribera (Ponferrada). 
La voz sexmo utilizada en la Provincia de Segovia falta en Aut. que trae alfoz con esta acepción: «Término y pago dentro de un distrito que lo comprende».

De las voces abadía, condado, granja, marquesado, merindad, obispalía (poco usado, dice Aut.), quintería, señorío, término (en el Vecindario va acompañado por despoblado o con jurisdicción), valle (muy frecuente en León, Burgos, Palencia, Granada) y venta (Palencia), sí trae Aut. acepciones con la significación de «territorio».

Merecen especial consideración las voces reino, provincia, partido, ciudad, villa, lugar y aldea. A causa del peculiar engrandecimiento de los primitivos núcleos cristianos medievales, frente a los musulmanes, la vieja palabra reino se utilizó desde un principio para designar a esos núcleos con un emplazamiento geográfico determinado y a veces frente a otros núcleos cristianos de rango inferior llamados condados; y así se decía Reino de Asturias, Reino de León, Reino de Navarra, Reino de Aragón; la capitalidad de tales entidades territoriales no era en los siglos medievales tan determinante como lo fue a partir del Renacimiento; lo que contaba era la Corona y como esta iba creciendo en poder a medida que conquistaba nuevos territorios, hacia el sur sobre todo, la voz reino designaba a esos territorios que se iban incorporando como nuevos sumandos: de ahí que se pudiera decir Reino de Galicia, de Toledo, de Valencia, de Murcia, de Granada, de Jaén, de Sevilla, etc. Como se ve por sus nombres, esos reinos pudieron haber tenido reyes musulmanes, con dinastías determinadas, como en el caso de Granada, pero, desde la perspectiva histórica cristiana eran esencialmente territorios con un nombre, topónimos. Esto explica que el plural reinos se utilizase durante siglos y que, en ciertos contextos, siga vivo hasta hoy; ese plural creo que contribuye a explicar el curiosísimo plural Las Españas, aunque este tenga también un fundamento latino en las expresiones España citerior y España ulterior, empleadas a partir de la romanización y usadas sobre todo en la prosa isidoriana. A partir del descubrimiento de América, esta idea de plural se vio reforzada por el plural Las Indias (sin artículo en muchos casos), territorios que estaban gobernados por virreyes y divididos en virreinatos, plurales también. Todo ello explica que en pleno siglo XvIII, bajo los centralistas Borbones, siguiera tan viva la voz reinos. En el Diccionario de Autoridades se lee en el Prólogo, p.V: «En el cuerpo de esta obra, y en el lugar que les corresponde, se ponen varias voces peculiares y propias, que se usan frequientemente en algunas provincias y reinos de España, como en Aragón, Andalucía, Asturias, Murcia, etc, aunque no son comunes en Castilla».

Como se ve, el autor del Prólogo del Diccionario de Autoridades usa en plural, con el valor genérico y abstracto de «territorios» las voces reinos y provincias. El propio Diccionario dice s.v. reino: «Una o muchas Provincias suje- 
tas a un Rey». Esta definición es buena prueba de cómo ambas voces, reino y provincia se confundían en muchos contextos más o menos retóricos.

La voz provincia, tan latina en forma y en significado, se define así en Aut.: «La parte de un Reino u Estado, que se suele gobernar en nombre del Príncipe, por un ministro que se llama Gobernador». Esta definición es de lo más abstracto y aplicada a la España de 1750 parece inexacta: cuando se redacta el Vecindario de Ensenada, veinte años después del Diccionario, la Corona de Castilla estaba formada por 22 Provincias pero no se habla nunca de Gobernadores; a propósito del Vecindario se habla de Contadores e Intendentes, quienes tenían, sobre todo, deberes y actividades fiscales; la voz gobernador debió adquirir mucha más vitalidad en el siglo XIX, probablemente a partir de la división de España en 50 provincias; yo creo que en la definición de Aut. es el empleo del infinitivo gobernar el que acarrea la aparición de la voz Gobernador. De las tres acepciones que trae Aut. s.v. gobernador ninguna alude al gobierno específico de los distintos territorios o partes de un Reino. También es revelador de la fluidez del significado de la voz provincia el ejemplo que añade el propio Diccionario de Autoridades s.v. id.: «Sandov. Chron. de D.Al.VII.cap.32. Fundó el Conde D. Rodrigo González Girón, en la Provincia de Liébana en Asturias de Santillana, el Monasterio de Santa María de Piasca». Concordando con este ejemplo, en el Vecindario de Ensenada y en la Provincia de Burgos, aparece como territorio dentro del Partido de Laredo, la Provincia de Liébana: es decir, que la misma palabra, provincia, designaba un territorio, reducido y remoto, que era parte de otro mucho más vasto y que recibía el mismo nombre.

No podemos extendernos acerca de las acepciones metafóricas que puede tener la voz provincia, pero estos ejemplos bastan para probar su relativa falta de solidez semántica, lo que ayudaría a explicar la facilidad con que, en años recientes ha surgido, a lomos de un nuevo texto constitucional, la flamante división del país en Autonomías. De la voz Partido ya vimos cuán irregular era su empleo en las 22 Provincias de la Corona de Castilla y también cómo, en muchos casos, su significado resultaba un tanto fluido. La definición que trae Aut. s.v. partido, $8^{\mathrm{a}}$ ac., parece confirmar esto, al introducir en ella la voz ciudad en estos términos: «Se llama también el distrito o territorio, que está comprendido de alguna jurisdicción o administración de una Ciudad principal, que se llama su cabeza. Lat. Tractus». Trae Aut. esta otra ac.: «Se toma también por el Territorio o Lugar en que el Médico u Cirujano tiene la obligación de asistir y curar, por el salario que se le señala»; esta ac. vivía aún en las hablas leonesas a mediados de este siglo referida al médico. La voz partido parece haberse reforzado mucho y con plenitud semántica a partir del momento en que se hizo acompañar del adjetivo judicial en la división administrativa del siglo XIX. 
De la voz ciudad dice Aut. s.v. id.: «Población de gentes congregadas a vivir en un lugar, sujetas a unas leyes, y a un gobierno, gozando de ciertos privilegios y exenciones, que los Señores Reyes se han servido de concederlas según sus servicios. Unas son cabezas de Reino, como Burgos, Toledo, León, Sevilla, etc. Otras tienen voto en Cortes, como las referidas, y Valladolid, Salamanca, Cuenca, etc. Viene del Latino Civitas, que significa lo mismo». «Significa también el Ayuntamiento o Cabildo, y los Diputados, o Procuradores de Cortes, que en virtud de los poderes que les otorgan, tienen la representación y voz de la Ciudad que los envía. Lat. Senatus». La primera de estas acepciones viene a confirmar el estereotipado uso de la voz reino acompañando a ciertos topónimos: de los cuatro que enumera Aut. Sevilla fue en algún momento un reino de taifa, o la capital de una taifa, y Burgos se convirtió en capital del Reino de Castilla cuando se independizó de León aunque no se dijese nunca Reino de Burgos.

De la voz villa dice Aut.: «Se llama hoy la población que tiene algunos privilegios, con que se distingue de la Aldea, como vecindad, y jurisdicción separada de la Ciudad. Lat. oppidum». De la imperfecta jerarquización hispánica, cultural y política, puede servir de ejemplo la inadecuación entre esta ac. de villa y el significado de villano, que, aunque designaba a los vecinos o habitantes no nobles de villas y aldeas, se había cargado desde siglos antes de valores peyorativos tales como «rústico», «descortés», «ruín», «indigno», etc. Cierto es que el fr. vilain revela una evolución semántica parecida.

De la voz lugar dice Aut. en su $3^{\text {a }}$ ac.: «Vale también Ciudad, Villa o Aldea; si bien rigurosamente se entiende por lugar la Población pequeña, que es menor que Villa, y más que Aldea. Lat. oppidum». Esta acepción «rigurosa» es la que le da Cervantes al comienzo del Quijote; probablemente era, y quizá sigue siéndolo, voz más empleada en lo que llamamos la España sureña, mientras que en la norteña se ha preferido, con el mismo significado, la voz pueblo, más general hoy en todas partes y muy viva en las hablas leonesas, como bien lo prueba la frecuencia del diminutivo afectivo pueblín. En este contexto, no deja de llamar la atención que aldea, un concepto esencial para comprender la totalidad de la repartición de la población, sea un arabismo. Aut. la define así: «Lugar corto, que no tiene jurisdicción sobre sí, ni Privilegio de Villa, según las leyes de Castilla: y sus moradores son vecinos de alguna Villa, o Ciudad, en cuyo distrito, término y jurisdicción están. Lat. Pagus, Oppidulum»; «Se llama también en muchas partes de España cualquiera granja, o quinta, aunque no tenga vecinos. Lat. Villa». Esta acepción explica las numerosísimas aldeas cuyos nombres empiezan por Villa aunque la idea central de ambas acepciones, muy semejantes las dos, sea la carencia de personalidad jurídica y fiscal del aldeano, del habitante de la aldea. Sería interesante saber si en las aldeas había siem- 
pre algún edificio de carácter religioso. También es curioso observar que los gentilicios correspondientes a todas estas voces son etiquetas que se les asignan desde un plano superior, quizá el de la Corte: los habitantes de tales núcleos de población nunca se llaman a sí mismos ciudadanos, villanos, lugareños y aldeanos sino solamente vecinos; de estas cuatro voces ciudadano siempre ha tenido ecos de prestigio y una cierta aureola literaria; las otras tres tienen algo o mucho de peyorativo; lugareño no figura en Aut.; parece que el colectivo villanage le suplía; lo define así Aut. «La gente del Estado llano en los Lugares. Lat. Plebs».

Las voces ciudad, villa y lugar aparecen también en el Censo de Ensenada 9 acompañadas de despoblados, ventas, términos redondos, granjas, cortijos y casas de campo; el cuadro adjunto permite al lector observar la distribución de cada uno de esos conceptos en las 22 Provincias.

\begin{tabular}{lrrrrrrr}
\hline & & & & \multicolumn{3}{c}{ Términos redondos } & Cortijos o \\
& Ciudadanos & Villanos & Lugareños & Despoblados & Ventas & y granjas & casas de campo \\
\hline Galicia & 7 & 81 & 3202 & & & 667 & 67 \\
León & 3 & 290 & 4757 & 62 & & 91 & 42 \\
Burgos & 6 & 588 & 1191 & 13 & & 53 & \\
Palencia & 1 & 120 & 187 & 21 & 2 & $16+5$ & 8 \\
\hline Zamora & 1 & 59 & 186 & 25 & & 81 & 6 \\
Toro & 1 & 83 & 229 & 35 & 9 & 24 & 23 \\
Valladolid & 2 & 171 & 354 & 67 & 1 & 24 & 210 \\
Salamanca & 2 & 134 & 702 & 173 & 0 & 57 & 5 \\
Ávila & 1 & 90 & 207 & 128 & 6 & 12 & 18 \\
Segovia & 1 & 100 & 302 & 143 & 14 & 22 & 14 \\
Soria & 4 & 132 & 482 & 83 & 5 & 30 & 24 \\
Guadalajara & 2 & 187 & 110 & 18 & 7 & 9 & 23 \\
\hline Madrid & & 73 & 17 & 6 & 7 & 3 & 79 \\
Cuenca & 2 & 232 & 186 & 52 & 5 & $2+12$ & $0+763$ \\
Toledo & 2 & 229 & 100 & 123 & 33 & 25 & 1680 \\
Extremadura & 7 & 230 & 133 & 14 & 3 & & 2993 \\
\hline Mancha & 2 & 93 & 93 & 4 & 20 & 4 & 3543 \\
Murcia & 5 & 60 & 1 & 1 & 24 & & 18151 \\
Jaén & 5 & 58 & 11 & 3 & 19 & 0 & 3940 \\
\hline Córdoba & 4 & 55 & 0 & 0 & 22 & 35 & 3185 \\
Granada & 17 & 182 & 158 & 3 & 38 & 24 & 13279 \\
Sevilla & 15 & 160 & 26 & 33 & 51 & 479 & 2505 \\
\hline & & & & & & &
\end{tabular}

${ }^{9}$ Censo de Ensenada, 1756, Introducción Pedro Carasa Soto, 1993, Madrid. Tabapress, S.A. 
Se echa de ver enseguida la distinta distribución, entre la España norteña y la sureña; en la primera hay muchísimos más lugares que en la segunda, en especial en la España húmeda y atlántica; en la segunda hay muchas más ciudades y sobre todo muchísimos más cortijos o casas de campo, en especial en Murcia y en Granada, provincia esta que ofrece otras particularidades dada su orografía; el contraste entre norte y sur también se da en las ventas, mucho más abundantes en el sur; en el Censo se equipara en el encabezamiento términos redondos y granjas, por una parte, y por otra cortijos y casas de campo (salvo en alguna Provincia que las separa). El título general dice: Relación de las poblaciones, edificios e individuos de que se compone esta Provincia; a pesar de la claridad del enunciado, la mayor parte de las Provincias no separa el número de edificios civiles, y en la columna donde pone Número de Edificios coloca la lista de los núcleos de población; ello se debe a que el interés de los Contadores estaba en este caso en contar los edificios religiosos: catedrales, conventos iglesias, hospitales, etc. De una u otra manera son respetuosas con el epígrafe Galicia, Burgos, Salamanca, Segovia, Soria, Valladolid y Zamora, las cuales, de modo diverso pero específico dan el número de casas e incluso a veces el de pajares y molinos. Otras particularidades son que en Galicia se lee Lugares o feligresías y en el de Murcia, además de los miles de cortijos, hay 4437 barracas. En cuanto a los Despoblados (voz de significado no muy claro) se observará que, con la excepción de Toledo, abundan mucho más en el norte, con la excepción de Galicia donde no hay ninguno; en las Provincias que especifican el número de edificios suele ser mayor el número de los Despoblados que el de los edificios ubicados en ellos, excepto en Soria, donde ocurre lo contrario; en el caso de Burgos van juntos Despoblados y ventas; Segovia desglosa casas de campo de pajares, molinos y demás edificios. En cuanto a los Despoblados tampoco coincide muchas veces el número que ofrece el Censo y el que de la misma Provincia trae el Vecindario; por ejemplo, para Cuenca, el Censo da 52 Despoblados y en el Vecindario hay sólo 10; para Extremadura el Censo da 14 y el Vecindario sólo 2.

Ya dimos más arriba el significado que Aut. ofrece de la voz Despoblado. De venta dice en su $3^{\text {a }}$ ac.; «Se llama asimismo la casa establecida en los caminos, y despoblados para hospedaje de los pasajeros. Díjose así porque en ella se les vende lo que han menester». No es de extrañar, por tanto, que en el caso de Burgos vayan juntos los dos conceptos: Despoblados y ventas 13, número de edificios 4; cabe imaginar que si había solo 4 edificios serían 4 ventas, poquísimas para una Provincia de sus dimensiones.

En Aut. no aparece término redondo a pesar de las numerosas acepciones de la voz término, una de las cuales es, naturalmente, la de un territorio donde está situada una población; en la mayor parte de las Provincias se identifica 
con la voz granja; en algunas figura solo Términos redondos; en Palencia Términos redondos y como concepto distinto Granjas con término; también se separan en Cuenca; en Zamora dice 81 dehesas o términos redondos (68 edificios); en Granada, aparte de los cortijos propiamente dichos, se lee: Términos redondos con nombre de cortijos; el concepto falta en Extremadura y Murcia y da cero para Jaén; llama la atención el crecido número que tienen Sevilla y Galicia. De la voz granja dice Aut.s.v.id: «Hacienda de campo cercada de paredes a modo de huerta, dentro de la cual suele haber una casería, donde se recoge la gente de labor y el ganado. Lat. Villa rústica, Suburbanum».

La denominación Cortijos o casas de campo parece definir la unidad de población más pequeña de todas. En las Provincias de Burgos, Palencia, Zamora, Toro, Valladolid, Salamanca, Ávila, Segovia, Madrid y Guadalajara no aparece la voz cortijo; Burgos tampoco trae casas de campo pero ofrece, como Valladolid, el número de molinos. A la vista del cuadro se observará que, además del empleo de la voz cortijo, el número de éstos aumenta extraordinariamente al sur de Madrid y alcanza cifras altísimas en Murcia y Granada; esta Provincia trae además el concepto puebla, voz anticuada según Aut. con el significado de «población». De la voz cortijo dice Aut. «Alquería, casería o casa destinada en el campo para recoger los frutos de la tierra. Es voz muy usada en los Reinos de Andalucía, Granada, Córdoba y otros vecinos Lat. villa, ae». De casa de campo dice Aut.: «Se llama la casa fabricada con jardines, fuentes y otros adornos que tienen algunos Príncipes y personas ricas para ir a divertirse y pasar algunas temporadas del año: las que regularmente suelen estar situadas en el campo, para huir del concurso de la gente. Lat. Domus voluptuariae». Ante estas acepciones parece evidente que las casas de campo a que se refiere el Censo de Ensenada son más bien granjas o, naturalmente, los cortijos sureños. De la voz barraca dice Aut.: «La choza o habitación rústica cubierta de fagina, que para defenderse de las inclemencias del tiempo disponen los que habitan en el campo, o los soldados cuando están en campaña, y no tienen tiendas. Es voz tomada del verbo Arábigo barracha, que vale ser humilde. Lat. casa, ae». La voz fagina designaba un haz de ramas delgadas para distintos usos. De todas las voces aquí comentadas lo más llamativo es la ausencia en el Diccionario de Autoridades de término redondo, expresión en la que el adjetivo tenía que haber significado algo; no hay que olvidar que la expresión números redondos aún goza hoy de lozanía; cierto es que parece inseparable de redondear con el sentido de suprimir algo que es casi superfluo o que vale poco; por otra parte el adjetivo redondo aparece en Aut. con cuatro acepciones metafóricas y de valor sustantivado muy curiosas pero hoy desaparecidas.

En conjunto creo que es posible advertir, además de la diversidad entre las varias Provincias, un cierto grado de vaguedad, de indefinición, en muchas 
de las voces que aparecen en el Vecindario y en el Censo de Ensenada y que tienen acepciones alusivas a los distintos tipos de población y a las diferentes clases de territorios. Esta fluidez, en conceptos que deberían ser rigurosamente distinguidos por los hablantes y por los escribanos de los documentos y textos en cuestión, revela un cierto desorden que no podía dejar de influir en la organización de lo que se llamaba entonces la Corona de Castilla.

\section{El léxico de las cabeceras del vecindario}

Hay que tener siempre presente que el Vecindario era inseparable y a la vez complemento del Catastro y del Censo del mismo ministro Ensenada. Como lo que este pretendía era unificar los variados tipos de tributos, uniformándolos en una Única Contribución, consiguiendo así al mismo tiempo una mayor justicia y equidad social, era natural que el ente que necesitaba tener censado fuese el llamado vecino, que en cierto modo, venía a ser equivalente del cabeza de familia. Esto explica las denominaciones de los distintos sujetos: vecinos útiles, id. jornaleros, pobres de solemnidad, habitantes y viudas pobres. Estas denominaciones, a primera vista tan claras, no lo eran en la práctica, como vamos a ver en seguida; las cuatro primeras se subdividían a su vez en nobles y pecheros, estos llamados a veces del Estado General, expresión donde la voz Estado tiene una significación hoy desaparecida. En el caso de las viudas hubo provincias que también las subdividieron en nobles y pecheras e incluso en nobles, pecheras y pobres, como ocurrió en las de Cuenca y Segovia. A esas cinco categorías añade el Vecindario de Ensenada otra más, la de los eclesiásticos seculares, es decir, los párrocos y demás sacerdotes de lo que hoy se llama clero diocesano.

En el Cuadro 2. Modelos de cabeceras utilizadas en los vecindarios provinciales $^{10}$, Concepción Camarero nos presenta los modelos que, con ligeras variantes, ofrecen las 22 Provincias para describir las categorías mencionadas de los sujetos fiscales. La profesora Camarero nos advierte en seguida que «no todas las Provincias entendieron lo mismo para cada uno de los epígrafes de las cabeceras de los respectivos Vecindarios. Para aclarar tan apasionante cuestión — sigue diciendo- disponemos de dos fuentes: las notas recogidas al pie de algunos Vecindarios y la correspondencia cruzada entre las Provincias y la Real Junta a dicho respecto» ${ }^{11}$. Luego se extiende sobre las disparidades de interpretación de los conceptos viuda, jornalero y habitante por parte de los distin-

\footnotetext{
${ }^{10}$ Vecindario de Ensenada, 1759, Vol. I, págs. XL-XLI.

${ }^{11}$ Ibid. p. LXXXVI.
} 
tos Intendentes o Subdelegados. Los aspectos fiscales de estas voces dificultan su perfecta comprensión por el lector actual y los editores de esta introducción no alcanzan la claridad que sería de desear. Las acepciones que de estas voces trae el Diccionario de Autoridades ayudan sin duda a entender mejor sus significados. De la voz vecino se nos dan cinco acepciones y nos interesan las tres primeras porque aluden de modo inequívoco a compartir con otros casa, barrio o pueblo, a tener casa y hogar en una población, participando en ella de las cargas o «repartimientos» aunque en el momento de tener lugar tales hechos no se viva en ella; la $3^{\text {a }}$ ac. especifica aún más: «Significa asimismo el que ha ganado domicilio en un Pueblo, por haber habitado en él tiempo determinado por la ley». En las definiciones de Aut. aparece el verbo habitar y el Diccionario recoge además del verbo, el adjetivo habitable y los nombres habitador «el que vive o reside en algún lugar o casa» y habitación, «El lugar o casa donde se mora o vive», pero, curiosamente no trae la voz habitante. La palabra habitador apuntaba más a la idea de domicilio que a la de individuo vivo. Esto quiere decir que si hoy decimos «Villafranca tiene 3.000 habitantes» 0 «3.000 almas», es porque la idea de «tener domicilio en tal población» se ha desviado hacia la idea más general de «formar parte del conjunto de dicha población». Esto se debe sobre todo al gran aumento de la población en general y de manera muy particular en las ciudades, que han ido haciéndose cada vez más grandes. La voz habitante solo muy lentamente ha ido ganando terreno en los pueblos pequeños y en las aldeas, y todavía hoy, cuando ya no existen apenas obligaciones y derechos contractuales como los que definían al vecino durante siglos, los habitantes de esos modestos lugares, cuando se presenta la ocasión, se ven a sí mismos más como vecinos que como habitantes. Ello se debe en gran medida al urbanismo, a la arquitectura, pues en las aldeas y pueblos es todavía normal que cada familia tenga su casa separada de «la del vecino».

Podemos preguntarnos hasta qué punto ha disminuido el empleo de la voz vecino: en los núcleos rurales aún vive aunque no haya necesidad de emplearla tanto como antes; en los urbanos se emplea hoy para designar a los ocupantes de las respectivas viviendas que comparten una entrada única y unos servicios comunes en un inmueble; el empleo más frecuente tiene lugar en las expresiones «la comunidad de vecinos», «las comunidades de vecinos», en plural en ambos casos; por otra parte, es palabra propia de la lengua escrita, es decir, de documentos administrativos o legales, pero nadie la emplea hoy como predicado del verbo «ser» en la lengua hablada, cosa que era normal en el siglo XVIII y siguió siéndolo hasta mediados del xx en los núcleos rurales. Como ya dijimos, llama la atención la ausencia de la voz habitante en Aut. pero igualmente curioso es el hecho de que esta palabra designase en las primeras décadas de 
este siglo a los pobladores de las aldeas leonesas de la ribera del Esla que carecían de yunta, de «pareja» como se decía en el habla local, razón por la que no alcanzaban la categoría de vecinos. Todo esto explica la fórmula de presentación de la Provincia de Salamanca, que dice así: «Relación de los Vecinos útiles, nobles, pecheros, jornaleros, pobres de solemnidad, habitantes sin domicilio fijo...». Estos habitantes, al carecer de casa, que debe ser lo que significa aquí domicilio fijo, estarían cerca de los pobres de solemnidad, quienes, en la práctica, podían tener casa, a menudo cedida caritativamente por alguien del mismo pueblo; en las aldeas y pueblos pequeños este tipo de pobre local solía pedir limosna en las aldeas de los contornos, pero, sí físicamente podía, ayudaba en ciertas labores agrícolas o ganaderas a los vecinos más pudientes, alguno de los cuales solía facilitarle alguna modesta edificación para que se alojara en ella. Estos pobres eran generalmente viudas, viudos o ancianos solteros, gentes con pocos parientes o procedentes de otra zona o región, lo que explica su relativo aislamiento familiar y social; su pobreza consistía en la carencia total de tierras en aldeas donde casi todos, en mayor o menor proporción, las tenían, y por esa razón si eran varones solían contratarse como pastores, vaqueros y yegüeros. Este tipo de distribución social duró en las zonas leonesas al menos hasta mediados de este siglo.

El concepto de vecino útil parece describir al cabeza de familia que era un contribuyente normal, es decir, que no tenía exenciones ni por su clase social ni por otra razón.

En el concepto de las viudas, la mayoría de las provincias escriben Viudas pobres, otras Viudas a secas. Como el concepto fiscal de las viudas no quedaba claro, hubo Provincias que se lo consultaron a la superioridad; Segovia lo hizo en estos términos: «Si las viudas útiles se deben estimar por vecinos y ponerlas en la misma casilla que van estos, o en otra separada, o omitirlas» ${ }^{12}$. Se observará que el adjetivo útiles de esta expresión y el útil que acompañaba a vecino tienen una significación que alude exclusivamente al aspecto fiscal.

El concepto de jornalero también se prestaba a la ambigüedad. Dice C. Camarero: «Si hay algo verdaderamente confuso en el catastro es precisamente lo referido a los jornaleros. Al hacer fijar «jornal» también a los hacendados y maestros artesanos pertenecientes al estado general, varones y en edad competente para la actividad (18 a 60 años), los pueblos y los subdelegados mismos terminan haciéndose un verdadero lío. Al vaciar las Respuestas Generales de León para extraer los datos que se recogen en el volumen B4 de esta obra, se palpa el problema. Muchos pueblos contestarán a este tenor: «Jornaleros de profesión hay

${ }^{12}$ Ibid. p. LXXXVII. 
X, pero si se consideran jornaleros a los labradores... entonces son Y». Surgen así designaciones pintorescas pero elocuentes: «jornaleros labradores», «jornaleros pastores», «jornaleros jornaleros». Esto explica que sean muchos los pueblos en que se declaran más jornaleros que vecinos, cuando en realidad el catastro preguntaba por vecinos, o sea, cabezas de familia, que fuesen jornaleros» ${ }^{13}$.

El Diccionario de Autoridades dice s.v. jornalero: «El que trabaja por su jornal»; s.v. jornal: «El estipendio que gana el trabajador por un día»; a jornal: «Modo adverbial, que se usa en los conciertos que los Architectos hacen de las fábricas, habiéndolas de trabajar, recibiendo y pagando los jornales diarios, a distinción de quando las ajustan por un tanto: y se extiende a otros géneros de trabajos». Con estas mismas acepciones vivieron el adverbio y los dos nombres en España hasta mediados de este siglo, cuando la mecanización paulatina de las labores agrícolas redujo la necesidad de brazos y cambió totalmente la secular relación social; los jornaleros eran gentes del mismo pueblo, o de otro muy próximo, que, poseyendo poca tierra, acababan antes que otros sus propias labores y estaban así en condiciones de ayudar a los más hacendados ganándose a la vez un jornal; estos jornaleros solían pagarse «por el San Miguel», cuando podían empezar a venderse productos de la cosecha; como indicamos más arriba podía haber pobres del pueblo que también «salían a jornal»; los verbos usuales para describir el hecho eran salir, ir, andar; el contrato de estos jornaleros de ambos sexos, según las labores agrícolas, era puramente verbal y su trabajo lo realizaban al lado del vecino para el que trabajaban; junto a este y su familia hacían también las distintas comidas del día o días que fuesen a jornal para él, pero como solían ser del mismo pueblo dormían en sus propias casas. En contraste con este tipo de contratación, cuando se encargaban unos pajares o una casa a un «carpintero», este solía «coger la obra por alto», «ajustarla por alto», es decir, que se empleaba y aún se emplea el mismo verbo ajustar que trae Aut. en la frase «a distinción de cuando las ajustan por un tanto». La expresión por alto, hoy menos frecuente ya que antes, significaba que el constructor se comprometía a hacer toda la obra, en un plazo determinado y por una cantidad determinada, lo que incluía materiales y mano de obra.

Esta es la significación que trae Aut. para pobre de solemnidad: «Se llama el que padece total necesidad, y pobreza, por la que se ve obligado a pedir limosna para mantenerse. Pudo haberse dicho, porque por lo regular concurren semejantes pobres a las solemnidades o fiestas. Lat. Egentissimus pauper, vel extrema laborans inopia». Parece muy atinada la opinión de Aut. acerca del origen de la expresión. En la lengua hablada se venía utilizando sólo la palabra pobre

${ }^{13}$ Ibid. p. LXXXIX. 
para designar a los mendigos que pedían limosna de casa en casa y de pueblo en pueblo, fenómeno que en la España rural duró hasta mediados de este siglo; la expresión pobre de solemnidad podía oírse a veces enfáticamente o en frases de tipo comparativo como «vive como un pobre de solemnidad», por ejemplo.

A guisa de conclusión puede afirmarse que el conjunto de voces que los textos de las reformas de Ensenada utilizan, para referirse a las distintas categorías de sujetos fiscales y a las distintas divisiones y subdivisiones territoriales de la Corona de Castilla, revelan una torpeza mental y lingüística por parte de los escribanos y demás redactores que no puede menos de llamar la atención, tratándose de conceptos que deberían estar muy claros para los administradores y los legisladores. La heterogeneidad de las realidades y de las situaciones sociales hispánicas solo en parte explica y justifica la falta de un mayor rigor lingüístico y mental. 